\title{
Event-based surveillance of food- and waterborne diseases in Europe: 'urgent inquiries' (outbreak alerts) during 2008 to 2013
}

C M Gossner (celine.gossner@ecdc.europa.eu) ${ }^{1,2}$, B de Jong ${ }^{1}$, C J Hoebe ${ }^{2,3}$, D Coulombier ${ }^{1}$, European Food and Waterborne Diseases Study Group ${ }^{4}$

1. European Centre for Disease Prevention and Control (ECDC), Stockholm, Sweden

2. School of Public Health and Primary Care (CAPHRI), Maastricht University Medical Center (MUMC+), Maastricht, the Netherlands

3. Public Health Service South Limburg, Geleen, the Netherlands

4. Experts in the study group are listed at the end of the manuscript

Gossner CM, de Jong B, Hoebe CJ, Coulombier D, European Food and Waterborne Diseases Study Group. Event-based surveillance of food-and waterborne diseases in Europe: 'urgent inquiries' (outbreak alerts) during 2008 to 2013. Euro Surveill. 2015;20(25): pii=21166. Available online: http://www.eurosurveillance.org/ ViewArticle.aspx?Articleld $=21166$

Article submitted on 14 May 2014 / published on 25 June 2015

During 2008 to 2013,215 outbreak alerts, also known as 'urgent inquiries' (UI), for food- and waterborne diseases were launched in Europe, the majority of them $(135 ; 63 \%)$ being related to salmonellosis. For $110(51 \%)$ UI, a potential food vehicle of infection was identified, with vegetables being the most reported category ( 34 ; $31 \%)$. A total of $28 \%(n=60)$ of the outbreaks reported had an international dimension, involving at least two countries (mean: 4; standard deviation: 2; range: 2-14). Participating countries posted 2,343 messages (initial posts and replies, excluding updates), with a median of 11 messages per urgent inquiry (range: 1-28). Of 60 multicountry UI, 50 involved between two and four countries. The UI allowed early detection of multicountry outbreaks, facilitated the identification of the suspected vehicles and consequently contributed to the timely implementation of control measures. The introduction of an epidemic intelligence information system platform in 2010 has strengthened the role of the Food- and Waterborne Diseases and Zoonoses network in facilitating timely exchange of information between public health authorities of the participating countries.

\section{Introduction}

Collecting laboratory-based surveillance data of food-borne pathogens, with the aim of detecting and responding to multicountry outbreaks, has long been established in the European Union (EU). Created in 1994, Salm-Net was the first European network for Salmonella surveillance [1], which was replaced in 1997 by Enter-net, covering surveillance of Salmonella and Shiga toxin-producing Escherichia coli (STEC) 0157, with the addition of Campylobacter in 2004 [2]. Looking beyond EU borders, the network was extended to include experts from the current countries of the EU (excluding Croatia), plus Australia, Canada, Iceland, Japan, New Zealand, Norway, South Africa and Switzerland [2]. In 2007, Enter-net activities were transferred to the European Centre for Disease Prevention and Control (ECDC) and the network was renamed the Food- and Waterborne Diseases and Zoonoses (FWD) network [3]. The network scope was broadened to cover six priority diseases: salmonellosis, campylobacteriosis, STEC infections, listeriosis, shigellosis and yersiniosis. The network was also extended to encompass Lichtenstein, Turkey and the United States (US). Thus, during 2008 to 2013,38 countries in five continents were included in the network.

One of the key activities inherited from Enter-net was an internationally agreed procedure to share outbreak alerts, so-called urgent inquiries (UI), among network members. UI are launched by participating countries or ECDC after observing an unusual increase in the number of food- and waterborne infections having potential for international spread. The main objective of the $\mathrm{UI}$ is to allow the detection of multicountry outbreaks and thereafter facilitate the investigations. While UI were communicated initially by fax and email, ECDC launched a web-based restricted-access communication platform, the Epidemic Intelligence Information System for FWD (EPIS-FWD) in March 2010, allowing nominated participants from public health authorities to post and access information in a structured format $[4,5]$ (Table 1).

A mean of 5,392 (standard deviation (SD): 173) FWD outbreaks were reported annually during the study period in the EU and European Economic Area (EEA) countries [6-11]. About $95 \%$ of these outbreaks are point source outbreaks, i.e. where exposure happened at only one 
Event-based surveillance systems ${ }^{\mathrm{a}}$ for food- and waterborne diseases in the European Union/European Economic Area

\begin{tabular}{|l|c|c|c|}
\hline System & Coordinating body & Role of the systems & Participants \\
\hline $\begin{array}{l}\text { Epidemic Intelligence Information } \\
\text { System for Food-and Waterborne } \\
\text { Diseases and Zoonoses (EPIS-FWD) }\end{array}$ & $\begin{array}{c}\text { European Centre for Disease } \\
\text { Prevention and Control } \\
\text { (ECDC) }\end{array}$ & $\begin{array}{c}\text { Detection of multicountry food-and } \\
\text { waterborne diseases outbreaks and } \\
\text { assessment of the risk }\end{array}$ & $\begin{array}{c}\text { Public health authorities in EU/ } \\
\text { EEA countries plus Australia, } \\
\text { Canada, Iceland, Japan, New } \\
\text { Zealand, Norway, South Africa } \\
\text { and Switzerland }\end{array}$ \\
\hline $\begin{array}{l}\text { Early Warning and Response } \\
\text { System (EWRS) }\end{array}$ & European Commission & $\begin{array}{c}\text { Risk management of international or } \\
\text { unexpected events }\end{array}$ & $\begin{array}{c}\text { Public health authorities in EU/ } \\
\text { EEA countries }\end{array}$ \\
\hline $\begin{array}{l}\text { Rapid Alert System for Food and } \\
\text { Feed (RASFF) }\end{array}$ & $\begin{array}{c}\text { Risk management of } \\
\text { European Commission } \\
\text { serious rom food or feed }\end{array}$ & $\begin{array}{c}\text { Food safety authorities in EU/ } \\
\text { EEA countries and specific } \\
\text { agreements with non-EU/EEA } \\
\text { countries }\end{array}$ \\
\hline
\end{tabular}

EU/EEA: European Union/European Economic Area.

place, often a result from mishandling of food in restaurants or at home and leading to small and localised outbreaks. Only a small proportion of these outbreaks have the potential to affect multiple countries and those are the ones that the UI aim to capture. While participation in the UI system is voluntary, EU/EEA countries must report international or unexpected events to the Early Warning and Response System (EWRS) and through the International Health Regulations (IHR) $[12,13]$ (Table 1). Events for which there is evidence that cases in different countries are linked and/or that a food vehicle is identified and potentially exported or imported and/ or foreign travellers may have been exposed should be reported to the EWRS. Similarly, EU/EEA food authorities should notify the European Commission and other food authorities through the Rapid Alert System for Food and Feed (RASFF) about serious risks to human health deriving from food or feed [14] (Table 1). Since 2003, yearly reporting of investigated FWD outbreaks to the European Food Safety Authority (EFSA) has been mandatory for EU/EEA countries [15].

The objective of this study was to describe the UI during 2008 to 2013 , to measure the performance of the $\mathrm{UI}$ as an event-based surveillance system to detect multicountry outbreaks, and to analyse them in a more global EU/EEA surveillance context while looking at the link with other reporting systems. In addition, we aimed to evaluate the acceptability of the EPIS-FWD as a supporting platform.

\section{Methods}

We extracted UI details exchanged by fax and email and through EPIS-FWD from January 2008 to December 2013. For each urgent inquiry, we collated the following variables on a spreadsheet: disease, pathogen, date of launch of the UI and initiating country of the UI, number of cases and vehicle of infection. Epidemiological (person, place and time) and microbiological information (laboratory results) were used to identify a possible multicountry dimension of an outbreak. Ul for which different countries reported cases with indistinguishable pulsed-field gel electrophoresis (PFGE) pattern, same multiple-locus variable-number of tandem-repeats analysis (MLVA) profile or similar RNA sequence within a defined time period were considered possible multicountry outbreaks. For rare Salmonella serotypes, serotype information was sufficient to define if cases might be part of a multicountry outbreak. Vehicles of infections were divided in two categories: 'unknown' and 'suspected or confirmed'. EU/EEA countries were grouped into four geographical regions according to the United Nations, Department of Economic and Social Affairs [16]: eastern, northern, southern and western Europe (Figure 1). To further define the characteristics of the UI, we collected complementary information from peer-reviewed articles, outbreak reports, press releases, and ECDC and EFSA reports, by searching on national public health websites, ECDC and EFSA websites, PubMed and Google with keywords relevant to the disease being studied. We also asked countries to update the information in EPIS-FWD.

The data were analysed with Microsoft Excel 2010 and Stata 12.1. Seasonality was analysed using a fivemonth moving average. Significance of the difference in proportions was tested using chi-squared test.

We assessed the performance of the UI system through the following: the activity of the participating countries; the threshold for launching UI (number of cases triggering the UI); and the capacity of the system to detect multicountry outbreaks (percentage of UI that were multicountry outbreaks was taken as a proxy measure for this). We evaluated the acceptability of the EPIS-FWD through the comparison of UI characteristics before and after the introduction of the platform. We consulted the EWRS and RASFF platforms to identify whether UI-associated notifications were issued. As this study focuses on EU systems, IHR notifications were not included in the analysis. 
Geographical classification of European Union/European Economic Area countries
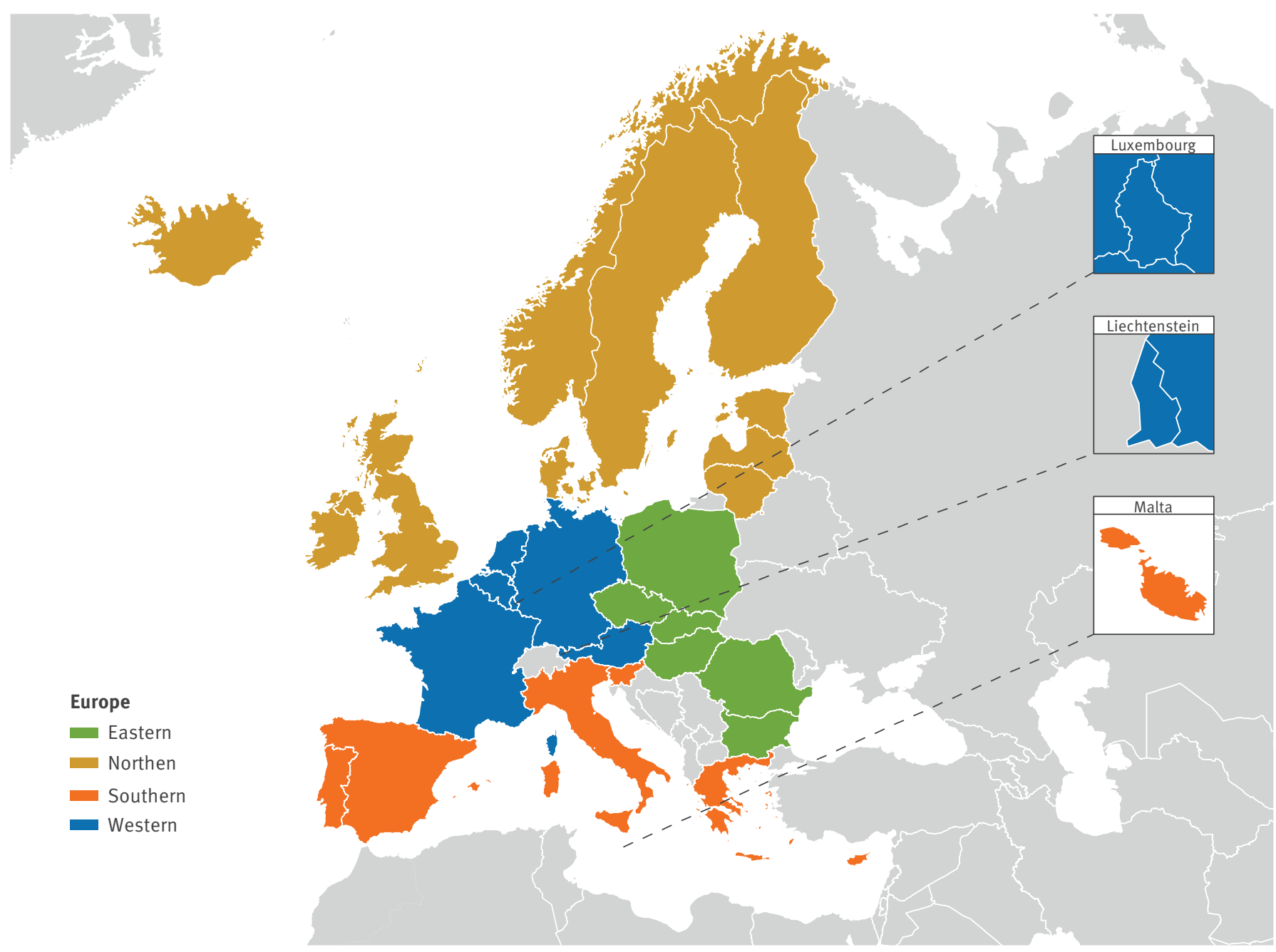

Source of the classification: United Nations, Department of Economic and Social Affairs [16].

\section{Results}

General characteristics of urgent inquiries

Between January 2008 and December 2013, 215 UI were issued by participating countries (Figure 2). The number of $\mathrm{UI}$ fluctuated over the years, with $32 \mathrm{UI}$ in 2008, 27 in 2009, 33 in 2010, 49 in 2011, 32 in 2012 and 42 in 2013 .

The moving average highlights some seasonality in the northern hemisphere, with peaks during spring and summer. One peak in November 2010 did not follow this seasonal pattern. In addition, a larger peak was visible in the summer and autumn of 2011, with $34 \mathrm{UI}$ launched between June and November.

A total of 20 of 30 EU/EEA countries, four of eight nonEU/EEA countries and ECDC initiated the UI. Only one urgent inquiry was launched by a country from the southern hemisphere. Countries in northern and western Europe launched the majority of the UI, with 117 (54\%) and 54 UIs (25\%), respectively (Figure 3). The countries from northern and western Europe launched respectively 31 and 13 multicountry UI.

The majority of the UI were posted by the United Kingdom $(n=27)$, France $(n=21)$ and Denmark $(n=$ 20). Among the participating non-EU/EEA countries, the US posted the most UI $(n=18)$. One of the UI was launched by ECDC on behalf of Israel.

The rate of $\mathrm{UI}$ per million inhabitants in EU/EEA countries shows a pattern, with countries in northern Europe posting the most UI, followed in order by countries in western, eastern and southern Europe (Figure 4).

Participating countries posted 2,343 messages (initial posts and replies, excluding updates), with a median of 11 messages per urgent inquiry (range: 1-28). After launch of EPIS-FWD in 2010, the number of messages posted increased. From 272 and 235 messages in 2008 and 2009 respectively, the number of messages rose to 315 in 2010, 582 in 2011, 450 in 2012 and 485 in 2013. The mean number of messages per urgent inquiry 


\section{FIGURE 2}

Number of urgent inquiries and five-month moving average, by month, participating countries of the northern hemisphere ${ }^{\text {, }}$ $2008-13(n=214)$

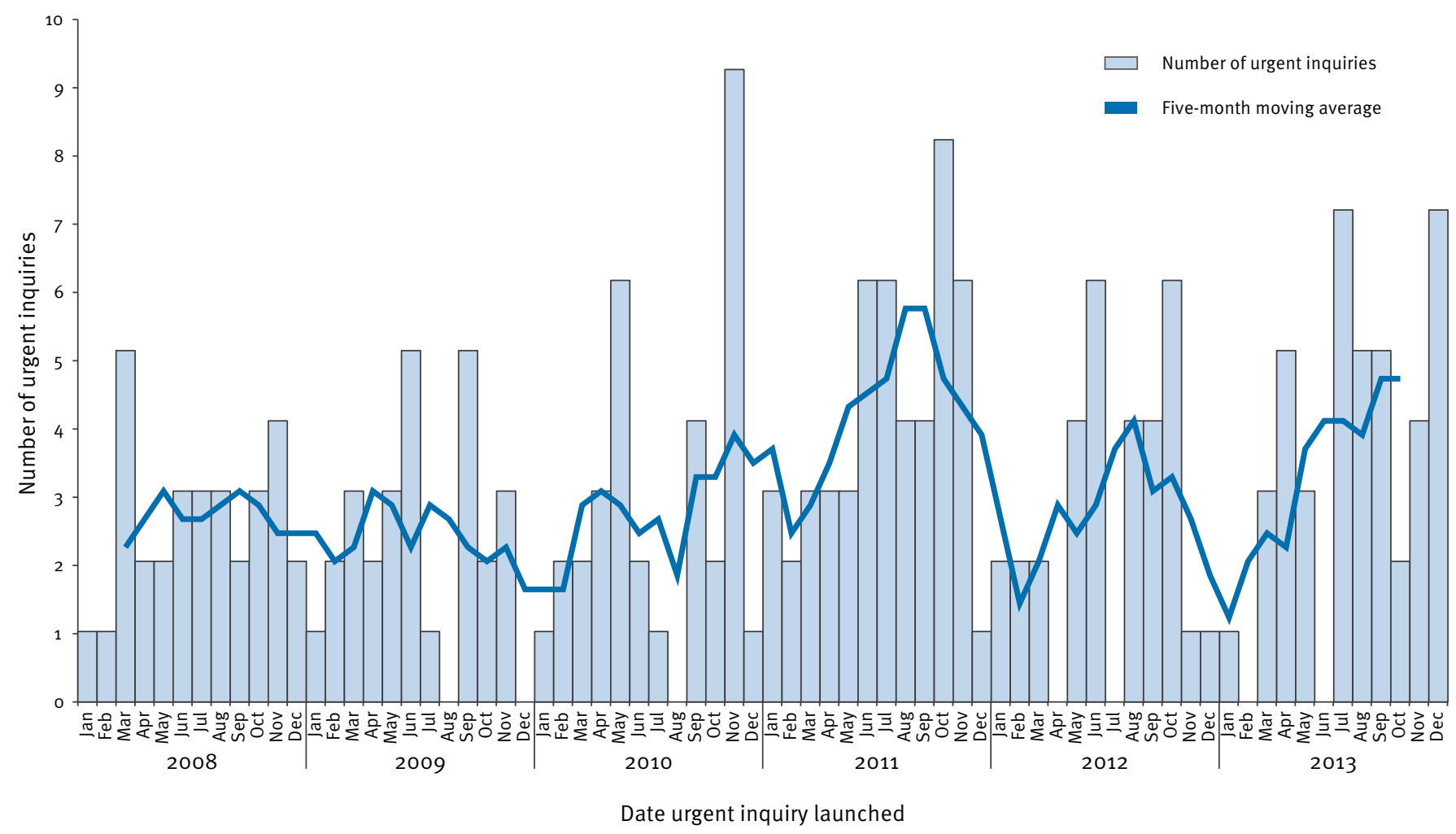

${ }^{a}$ Current countries of the European Union/European Economic Area (excluding Croatia), plus Canada, Japan, Switzerland, Turkey and the United States.

increased from 2008 to 2012, and decreased in 2013 (Figure 5).

\section{Pathogens and vehicles of infection}

A total of 15 diseases and intoxication syndromes were reported (Table 2). Salmonellosis and STEC infection represented $63 \%(n=135)$ and $15 \%(n=32)$ of the UI, respectively. A total of 50 Salmonella serotypes were reported: the two most commonly reported were $S$. Typhimurium $(n=34)$, including its monophasic variants 1,4,[5],12:i:-, and S. Enteritidis $(n=22)$. Seven STEC serogroups were reported, of which serogroup 0157 was the most predominant $(n=20 / 32)$. Other serogroups reported included $026,027,0104,0121$, 0145 and 0177.

For $110 \mathrm{UI}$ (51\%), a food vehicle of infection was either suspected or confirmed, through descriptive and/or analytical epidemiological studies. This proportion was relatively stable between 2008 and 2013 (range: $36-67 \%$ ). For $93 \mathrm{UI}$, the vehicle or origin of infection remained unknown. For seven UI, the infection was due to direct contact with animals; for four, it was water; and for one, it was a laboratory-acquired infection [17].

Three waterborne outbreaks were related to cholera in countries outside the EU where European travellers were at risk of infection and the remaining outbreak was a local outbreak of cryptosporidiosis after contamination of the drinking water.

The most commonly reported food vehicles were vegetables $(n=34)$, followed by pork $(n=14)$, beef $(n=$ 12), eggs $(n=7)$, cereal products $(n=7)$ and fruit $(n=$ 7) (Figure 6). A large increase in number of UI related to vegetables was observed in 2011 , followed by a decrease in 2012 and 2013. There were fewer UI related to pork in 2012-13 compared with the 2008-11 (except 2009, when there was no urgent inquiry related to pork).

\section{Affected countries and exposure}

Most of the UI $(155,72 \%)$ involved a single country, meaning that no linked cases could be identified by ECDC in other countries. The mean number of country involved in multicountry UI was four (SD: 2; range: 2-14). Of the 60 multicountry UI, 50 involved between two and four countries. In $10 \mathrm{UI}$, at least five countries were involved per urgent inquiry, including an outbreak of S. Stanley infections in the EU in 2012 [18] and hepatitis A associated with travel to Egypt in 2013 [19]. Multicountry outbreaks were primarily due to the distribution of a contaminated product to multiple countries ( 35 outbreaks) and to the travel of people to a common country/place of infection (19 outbreaks). International trade of infected animals was reported in two UI. For 


\section{FIGURE 3}

Single country and multicountry urgent inquiries initiated by participating countries ${ }^{\mathrm{a}}$ and the European Centre for Disease Prevention and Control, 2008-13 (n = 215)

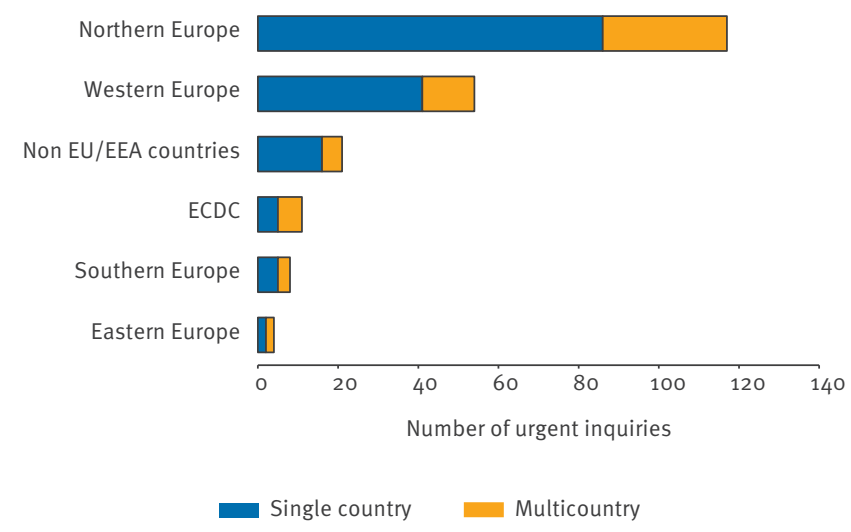

ECDC: European Centre for Disease Prevention and Control; EU/ EEA: European Union/European Economic Area.

a Current countries of the EU/EEA (excluding Croatia), plus Australia, Canada, Japan, New Zealand, South Africa, Switzerland, Turkey and the United States. Geographical classification of EU/ EEA countries according to the categories of the United Nations, Department of Economic and Social Affairs [16].

four UI, the information available was insufficient to define the exposure.

A total of $31 / 117(26 \%)$ of the UI launched by countries in northern Europe were multicountry outbreaks (Figure 3). A similar proportion of multicountry outbreaks was observed among countries of western Europe (13/54) and non-EU/EEA countries (5/21). For countries in southern and eastern Europe, numbers of UI were too small to obtain a meaningful comparisons for these regions. No region was, however, statistically significantly more likely to launch UI that became multicountry.

\section{Number of cases triggering an urgent inquiry}

For $76 \mathrm{UI}$ (35\%), the trigger for posting the UI was less than 10 human cases and for $19 \mathrm{UI}$ (9\%) the trigger was above 100 cases (median: 15; range: 0-8,138). Six UI were launched after identification of a contaminated food product, without any human cases initially reported. The $\mathrm{UI}$ launched with the highest number of cases $(8,138$ cases) was related to a large outbreak of cholera in Haiti in 2010 and can be considered as an outlier [20].

Of the $76 \mathrm{UI}$ with a trigger below 10 cases, 42 and 16 were posted by countries in northern and western Europe, respectively.

The median number of cases triggering the UI decreased over the years: 29; range 3-1,375 (in 2008), 18; range: 0-60o (2009), 20; range: $2-8,138$ (2010), 9; range $0-250$ (2011), 12; range 1-267 (2012) and 11; range $0-391$ (2013). A total of $19 \mathrm{UI}$ with a trigger below
10 cases and 6/19 UI with a trigger above 100 cases appeared to be multicountry outbreaks. The mean number of cases triggering UI differed by disease; for instance, for listeriosis, salmonellosis and STEC infection, respectively, the mean was 14 (SD: 16), 59 (SD: 170) and 21 (SD: 46).

No statistically significant associations were observed between the geographical regions, the number of cases triggering the $\mathrm{UI}$ and the multicountry aspect of the UI.

\section{Links with other alert systems}

For $41 \mathrm{UI}$, an EWRS was launched: $26 \mathrm{UI}$ were launched before an EWRS message was issued, eight were posted after an EWRS message was issued and seven were posted the same day. For the last two situations, the UI were used to collect epidemiological and microbiological information to assess the situation better, but implied that information was scattered between the two platforms.

For 26 of the 60 multicountry outbreaks, an EWRS message was launched. Between 2008 and 2013, 105 EWRS messages were issued about FWD events, among which 36 were multicountry events. The majority of the EWRS messages on FWD related to salmonellosis $(n=29)$, botulism $(n=13)$ and hepatitis $A(n=13)$. A total of $44(42 \%)$ and $56(53 \%)$ of those 105 EWRS messages reported the risk of a contaminated food product potentially distributed internationally and the risk of travellers getting infected while abroad (including infection on cruise ships), respectively. Among the 64 EWRS on FWD events that were not reported as UI, two salmonellosis outbreaks could potentially have been investigated first through UI: one reported by the European Commission on behalf of Switzerland in 2008 and one outbreak connected to campsites and restaurants in southern Sweden in 2010.

For $46 \mathrm{UI}$, at least one RASFF notification was issued. For 14 of the $27 \mathrm{UI}$ that involved at least one EU/EEA country, were linked to the distribution of a contaminated product and for which a vehicle of infection was suspected or confirmed, a RASFF notification was issued. For 22 events, the UI were launched first; for 20 events, the RASFF notification was launched first; and for four events, they were launched the same day.

\section{Discussion}

\section{Key performance of urgent inquiries}

With a mean of three UI per month (SD: 2) between 2008 and 2013, an increasing number of messages exchanged, and a decreasing median number of cases triggering the UI, the UI are a well-established system that is increasingly trusted by the participating countries. More information is shared and outbreaks are likely to be reported at an earlier stage. Since 2010, EPIS-FWD has facilitated the exchange of information. 

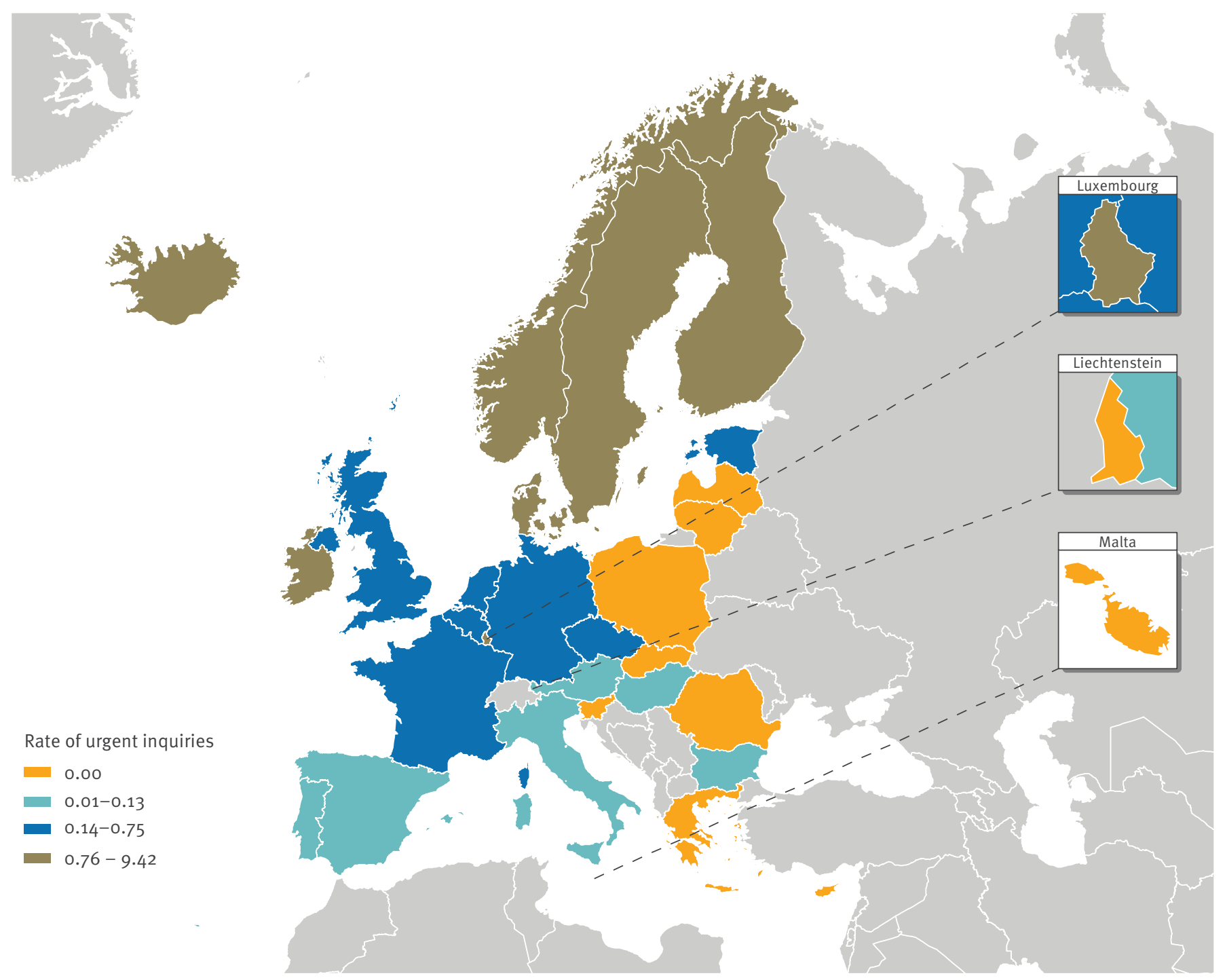

Rate of urgent inquiries

0.00

$0.01-0.13$

$0.14-0.75$

$0.76-9.42$

Divided by quantile. Source of population estimates: Eurostat 2011 [22].

Geographical classification of European Union/European Economic Area countries according to the categories of the United Nations, Department of Economic and Social Affairs [16].

The number of messages exchanged among participating countries did not seem to be an indicator for having multicountry outbreaks. The majority of the replies to $\mathrm{UI}$ were to report negative findings and/or provide background information useful for the investigations

Looking at the moving average (Figure 2), two main peaks in number of UI were observed: the first in November 2010 is unexplained; for the peak observed from June to November 2011, it is possible that following media attention on the outbreak of STEC $0104: \mathrm{H}_{4}$ infection in Germany in 2011, network members increased the sensitivity of their surveillance systems and decreased the threshold to launch UI.

$\mathrm{UI}$ are slightly marked by the seasons. While outbreaks related to mishandling of food (home or restaurant) are quite affected by the seasons - with faster growth of microorganisms in warmer temperatures and inadequate cooking or contamination of food at barbeques or parties - outbreaks related to distribution of contaminated commercial food items are likely to be less affected by the seasons, but rather by breach of contamination barriers in the production chain, resulting in less marked seasonal patterns.

A total of 10 EU/EEA countries did not launch any UI during the study period. Considering the difference in number and rate of $\mathrm{UI}$ launched by participating countries, the threshold to launch UI appears to be extremely variable, with the countries in northern and western Europe having the lowest threshold for posting an UI. This is confirmed by the fact that the majority of the UI triggered by less than 10 cases were launched by countries of these two regions. Considering the absence of association between the region and 


\section{TABLE 2}

Urgent inquiries launched per disease or intoxication syndrome, participating countries ${ }^{\mathrm{a}}, 2008-13(\mathrm{n}=215)$

\begin{tabular}{|l|c|}
\hline Disease or intoxication syndrome & $\begin{array}{c}\text { Number } \\
\text { of urgent } \\
\text { inquiries }\end{array}$ \\
\hline Salmonellosis & 135 \\
\hline Shiga toxin-producing Escherichia coli infection & 32 \\
\hline Listeriosis & 11 \\
\hline Shigellosis & 7 \\
\hline Hepatitis A & 7 \\
\hline Cryptosporidiosis & 5 \\
\hline Norovirus infection & 4 \\
\hline Cholera & 3 \\
\hline Botulism & 3 \\
\hline Food poisoning due to toxins & 2 \\
\hline Yersiniosis & 2 \\
\hline Trichinellosis & 1 \\
\hline Paratyphoid fever & 1 \\
\hline Cyclosporiasis & $\mathbf{2 1 5}$ \\
\hline Brucellosis & 1 \\
\hline Total & 7 \\
\hline
\end{tabular}

a Current countries of the European Union/European Economic Area (excluding Croatia), plus Australia, Canada, Japan, New Zealand, South Africa, Switzerland, Turkey and the United States.

multicountry aspect of the UI, it is suspected that outbreaks, including multicountry outbreaks, were underreported in countries of eastern and southern Europe. The UI system is dependent on the capacity and willingness of participating countries to launch and reply to an UI. While the focus of the UI is to detect multicountry outbreaks, the majority of the UI involved one single country. It was not possible to identify the criteria that make UI become multicountry investigations.

The threshold number of cases to launch UI differed with the reported disease, with UI for listeriosis and STEC infections having a lower threshold than, for instance, salmonellosis. This could be explained by the relative severity of the diseases.

Two thirds of the multicountry outbreaks were due to the distribution of a contaminated product and one third were related to travel to one country or place of infection. Multicountry waterborne outbreaks are likely to be travel related. For both distribution of contaminated products and travel-related outbreaks, it is through the gathering and cross-matching of information that the multicountry dimension of an outbreak can be identified. As there was no association between number of cases as a threshold of $\mathrm{UI}$ and being a multicountry outbreak, all clusters/outbreaks with potential international spread should be reported, even if detected at a late stage.
The reasons for the striking variations in $\mathrm{UI}$ reporting are unclear. Structural and cultural differences in the organisation of national public health systems are possible explanations. There are striking variations between countries with respect to their surveillance systems, including their laboratory capacity for detection, identification and typing of gastrointestinal pathogens. Some countries, therefore, have very limited capacity to detect and investigate outbreak signals [21]. Considering the important variation in the number of UI launched per countries and the number of their replies, ECDC should further encourage all countries to participate actively in the system. Negative responses are also of practical value to a national outbreak control team, as they actively confirm that other countries have not detected associated cases.

The active participation of non-EU/EEA countries confirms the perceived added value of the UI. While not part of the network, Israel used the UI through ECDC to investigate a national outbreak in 2011. Such requests from countries outside the network should be evaluated and, as much as possible, facilitated by ECDC.

\section{Representativeness of urgent inquiries regarding outbreaks occurring in the European Union/European Economic Area}

The majority of the outbreaks reported to EFSA during the study period were caused by Salmonella spp. [6-11] and similarly Salmonella was the leading pathogen for which UI were launched. This was expected, as laboratories commonly test for and report this pathogen, and serotyping and molecular typing can be very effective

\section{FIGURE 5}

Mean number of messages ${ }^{\mathrm{a}}$ per urgent inquiry per year, participating countries ${ }^{\mathrm{b}}, 2008-13$

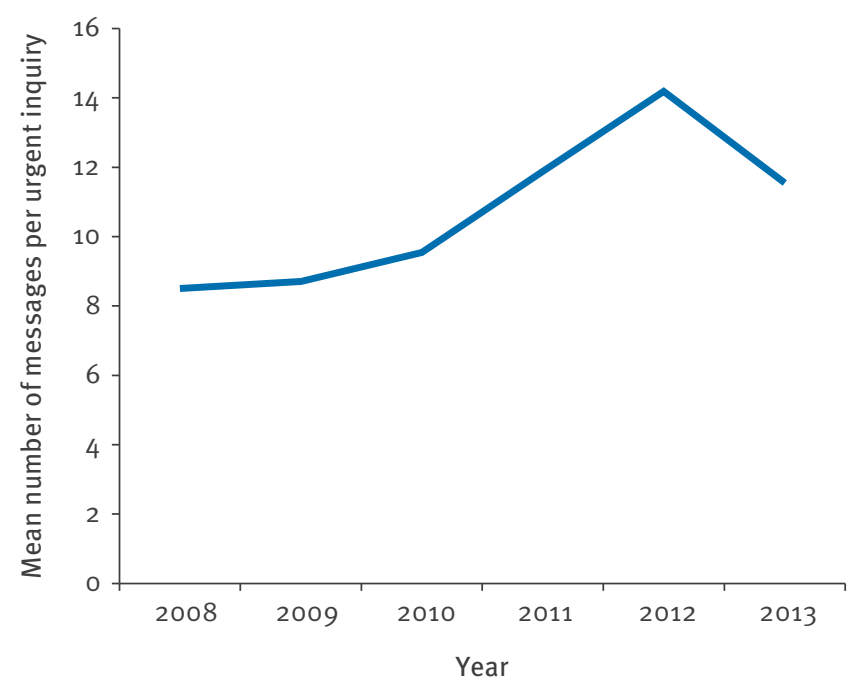

a Comprises initial posts and replies, excluding updates.

b Current countries of the EU/EEA (excluding Croatia), plus Australia, Canada, Japan, New Zealand, South Africa, Switzerland, Turkey and the United States. 


\section{FIGURE 6}

Urgent inquiries by categories of food vehicle of infection, participating countries ${ }^{\mathrm{a}}, 2008-13(\mathrm{n}=110)$

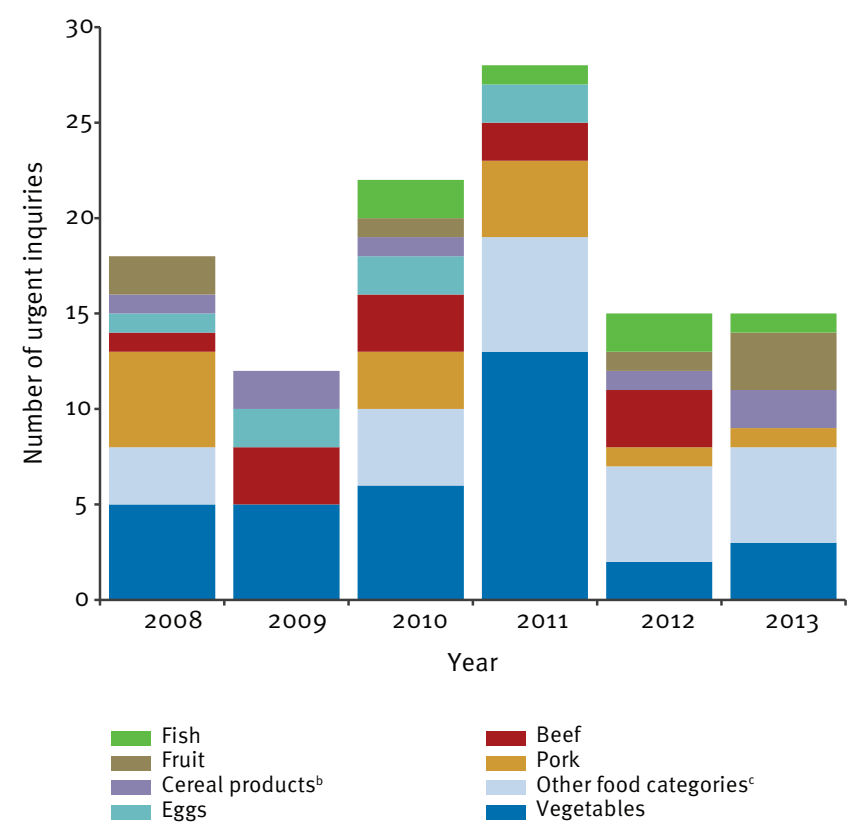

a Current countries of the European Union/European Economic Area (excluding Croatia), plus Australia, Canada, Japan, New Zealand, South Africa, Switzerland, Turkey and the United States.

b Cereal products includes rice and seeds/pulses.

'Other food categories include crustaceans, shellfish, molluscs, herbs and spices, mixed or buffet meals, canned food products, turkey meat, sweets and chocolate, infant formula, pet food, dietary supplements and other or unspecified poultry meat.

in detecting case clusters. Salmonella has a propensity to cause both point source and persistent source outbreaks, the latter being potentially cross-border outbreaks through food or animal trade. STEC and Listeria were the number two and three pathogens reported in UI, respectively, while outbreaks caused by these pathogens were least often reported to EFSA. STEC infection and Listeria outbreaks were infrequent in comparison with Salmonella outbreaks; however, the seriousness of the diseases, coupled with the availability of discriminative molecular typing methods mean that they are more likely to be reported.

UI may be particularly valuable for Listeria outbreaks because the disease does not have a high attack rate and listeriosis outbreaks are frequently due to consumption of manufactured products potentially distributed internationally (e.g. cheese, fish) rather than mishandling of food in restaurants or households as for Salmonella. Therefore, dispersed outbreaks are much more likely to be detected through the pooling of case information at the EU/EEA level [5].

While campylobacteriosis was the most commonly reported food-borne disease in the EU/EEA during the study period (mean: 212,987 cases (SD: 11,916); 471 outbreaks (SD: 89) [6-11], no UI were launched during the period studied. Campylobacter samples are not subtyped routinely and no discriminative and reliable subtyping system exists so dispersed, continuous outbreaks are therefore unlikely to be detected.

Whereas vegetables were the predominant vehicles of infection reported in the $\mathrm{UI}$, eggs were the main food vehicle category reported to EFSA [6-11], representing up to $18.5 \%$ of the outbreaks in 2013 [10]. One hypothesis is that eggs are more likely to be associated with point source outbreaks, such as in households or restaurants. It should be noted that the proportion of outbreaks due to vegetables reported to EFSA increased, from $1.9 \%$ in 2008 to $4.4 \%$ in 2013 (with a peak of $8.7 \%$ in 2010) [6-11]. The outbreak of STEC infection in Germany in 2011 potentially encouraged countries to report outbreaks linked to vegetables, which might explain the increase in number of vegetable-related UI that year. No explanation was identified for the peak in 2010.

\section{Links with other event-based surveillance systems}

Despite the existence of criteria for mandatory notifications, outbreaks reported as UI were inconsistently notified through EWRS and RASFF. This does not imply, however, that appropriate measures were not effectively implemented. All EWRS contact points have access to EPIS-FWD so that public health risk managers are kept informed.

ECDC, together with the European Commission, should develop guidance for reporting in the various existing risk assessment (EPIS-FWD) and risk management (EWRS and RASFF) platforms and should be more proactive in ensuring that EU/EEA countries report appropriately to these platforms. No RASFF notifications were issued for half of the UI that involved at least one EU/EEA country and were linked to the distribution of a contaminated product and for which a vehicle of infection was suspected or confirmed. A possible explanation for the lack of RASFF notification is that for these UI, a vehicle was suspected but no specific product or brand could be identified.

Despite a new version of EPIS-FWD, launched in July 2013, allowing any expert to be granted access to specific UI, food safety authorities still do not have default access to the platform. In the future, providing food safety authorities access to EPIS-FWD and creating an IT connection between EPIS-FWD and EWRS, and eventually RASFF, could be foreseen in order to streamline the exchange of information and ensure constant interaction between risk assessment and risk management.

In 2013, as ECDC established a molecular typing surveillance system for Salmonella, Listeria and STEC, a new version of EPIS-FWD was launched, integrating the management of clusters detected through molecular surveillance. With the development of molecular typing methods and their use in EU/EEA countries, ECDC will detect more and more multicountry microbiological 
clusters. Microbiological clusters considered to be relevant will be the trigger for ECDC to launch $\mathrm{UI}$ and therefore the number of $\mathrm{UI}$ is expected to rise in the coming years.

\section{Conclusion}

The UI proved to be successful in facilitating the detection of multicountry FWD outbreaks and became a key element of event-based surveillance of FWD outbreaks in the EU/EEA.

The introduction of the EPIS-FWD platform in 2010 has strengthened the role of the FWD network in facilitating the timely exchange of information between countries. Combined with data collected by EFSA on outbreaks, the $\mathrm{UI}$ give a good overview of the characteristics of FWD outbreaks reported at the EU/EEA level.

Our analysis shows the need to strengthen coordination between the risk assessors and risk managers at the EU/EEA level, particularly when reporting events to EPIS-FWD, EWRS and RASFF. This could be supported through the development of cross-sectoral guidelines for outbreak reporting.

As it was not possible to define any criteria that identify which events reported as UI would become multicountry outbreaks, guidelines for posting an UI should not be restrictive and participating countries should be encouraged to post an UI as soon as they detect any unusual FWD event.

Additional studies should be conducted in order to further assess the capacity of UI to detect multicountry outbreaks and to evaluate the impact of UI on the geographical spread of outbreaks and the resolution of outbreak sources.

\section{*Authors' correction}

On request of the authors, two experts from Bulgaria were added to the list of members of the European Food and Waterborne Diseases Study Group. This change was made on 8 July 2015 .

\section{Acknowledgments}

The authors would like to thank all the members of the FWD network for sharing data through the urgent inquiries. Further, the authors thank current and former ECDC colleagues who have participated to the monitoring and follow-up of the urgent inquiries during the studied period, particularly Johanna Takkinen, Therese Westrell, Nadia Ciampa, Ettore Severi and Annick Lenglet.

\section{Conflict of interest}

None declared.
Authors' contributions

CG collected the data, performed the data analysis and interpretation and drafted the manuscript. $\mathrm{BdJ}$ contributed to the data collection. BdJ, CH, JT and DC commented on the interpretation of the result and contributed to the writing of the manuscript. The Study Group contributed to collection and sharing of the data through the urgent inquiries, and commented on the manuscript. All authors read and approved the final manuscript.

Members of the European Food and Waterborne Diseases Study Group ${ }^{*}$

Agency for Health and Food Safety, Vienna, Austria (C. Kornschober, D. Schmid); Scientific Institute of Public Health, Brussels, Belgium (S. Quoilin); National Center of Infectious and Parasitic Diseases, Sofia, Bulgaria (K. Parmakova); National Reference Laboratory for Enteric Pathogens, Sofia, Bulgaria (P. Petrov); Ministry of health, Nicosia, Cyprus (M. Koliou); National Institute of Public Health, Prague, Czech Republic (R. Kralova, M. Marejkova); Statens Serum Institut, Copenhagen, Denmark (S. Ethelberg, L. Müller, M. Torpdahl, E. Møller Nielsen); Health Board, Tallinn, Estonia (J. Epstein, I. Dontsenko); National Institute for Health and Welfare, Helsinki, Finland (T. Lienemann, R. Rimhanen-Finne, M. Kuusi, A. Siitonen); French Institute for Public Health Surveillance, St Maurice, France (N. Jourdan-Da Silva, L. King); Institut Pasteur, Paris, France (S. Le Hello, A. Leclercq); Robert Koch Institute, Berlin, Germany (H. Bernard, C. Frank, D. Werber); National Reference Centre for Salmonella and other Enteric pathogens, Robert Koch Institute, Wernigerode, Germany (W. Rabsch); Hellenic Center for Disease Control \& Prevention, Attica, Greece (K. Mellou); National Centre for Epidemiology, Budapest, Hungary (K. Krisztalovics, J. Pászti); Centre for health security and communicable disease control, Reykjavik, Iceland (G. Sigmundsdottir, H. Hardardottir); Health Protection Surveillance Centre, Dublin, Ireland (P. Garvey, P. McKeown); National Salmonella, Shigella and Listeria Reference Laboratory, University Hospital, Galway, Ireland (M. Cormican); National Verocytotoxin E. coli Laboratory, Cherry Orchard Hospital, Dublin, Ireland (E. McNamara); Istituto Superiore di Sanità, Roma, Italy (G. Scavia, I. Luzzi); Centre for Disease Prevention and Control, Riga, Latvia (R. Korotinska); Centre for Communicable diseases and AIDS, Vilnius, Lithuania (G. Zagrebneviene); Health Promotion and Disease Prevention Directorate, Msida, Malta (A. Gatt); Norwegian Institute of Public Health, Oslo, Norway (K. Nygård, L. Vold, L.C. Thorstensen Brandal, A.L. Wester); Institute of Environmental Science and Research, Upper Hutt, New Zealand (M. Dufour); National Institute of Public Health, Bucharest, Romania (L. Zota); Public Health Authority, Bratislava, Slovak Republic (J. Mikas); National Institute of Public Health, Ljubljana, Slovenia (E. Grilc); Institute of Health Carlos III, Madrid, Spain (C. Varela Martínez, S. Herrera León); National Institute for Communicable Diseases, Johannesburg, South Africa (K. H Keddy); School of Public Health, University of the Witwatersrand, Johannesburg, South Africa (K. H Keddy); Swedish Institute for Communicable Disease Control, Stockholm, Sweden (S. Ivarsson, M. Löfdahl, C. Jernberg, I. Hedenström); National Institute for Public Health and the Environment, Bilthoven, the Netherlands (I. Friesema, L. Verhoef, W. van Pelt and M. Heck); Public Health England, London, United Kingdom (C. Lane, T. Peters, A. Awofisayo); Health Protection Scotland, Glasgow, United Kingdom (S. Brownlie); Centers for Disease Control and Prevention, Atlanta, United States (P. Gerner-Smidt). 
1. Fisher IS. Salm-Net: a network for human salmonella surveillance in Europe. Euro Surveill. 1995;0(0):7-8. PMID:12631753

2. International surveillance network for the enteric infections Salmonella, VTEC 0157 and Campylobacter. Enter-net annual report 2005. Surveillance of enteric pathogens in Europe and beyond. London: Enter-net surveillance hub, Health Protection Agency; 2007. Available from: http://staging.ecdcdmz.europa. eu/en/publications/Publications/316_annual_report2005.pdf

3. European Centre for Disease Prevention and Control (ECDC). Surveillance of six priority food-and waterborne diseases in the EU/EEA, 2006 - 2009. Stockholm: ECDC; 2013. Available from: http://www.ecdc.europa.eu/en/publications/ Publications/food-and-waterborne-diseases-surveillancereport.pdf

4. Gossner C. ECDC launches the second version of the EPIS-FWD platform. Euro Surveill. 2013;18(27). PMID:23870080

5. Yde M, Naranjo M, Mattheus W, Stragier P, Pochet B, Beulens $\mathrm{K}$, et al. Usefulness of the European Epidemic Intelligence Information System in the management of an outbreak of listeriosis, Belgium, 2011. Euro Surveill. 2012;17(38). PMID:23040965

6. European Food Safety Authority, European Centre for Disease Prevention and Control. The European Union summary report on trends and sources of zoonoses, zoonotic agents and food-borne outbreaks in 2011. EFSA Journal. 2013;11(4):3129. $250 \mathrm{pp}$. Available from: http://www.efsa.europa.eu/en/ efsajournal/pub/3129.htm doi:10.2903/j.efsa.2013.3129

7. European Food Safety Authority, European Centre for Disease Prevention and Control. The European Union summary report on trends and sources of zoonoses, zoonotic agents and food-borne outbreaks in 2010. EFSA Journal. 2012;10(3):2597. $442 \mathrm{pp}$. Available from: http://www.efsa.europa.eu/en/ efsajournal/pub/2597.htm doi:10.2903/j.efsa.2012.2597

8. European Food Safety Authority, European Centre for Disease Prevention and Control. The European Union summary report on trends and sources of zoonoses, zoonotic agents and food borne outbreaks in 2009. EFSA Journal. 2011;9(3):2090. 378 pp. Available from: http://www.efsa.europa.eu/en/efsajournal/ pub/2090.htm doi:10.2903/j.efsa.2011.2090

9. European Food Safety Authority, European Centre for Disease Prevention and Control. The Community summary report on trends and sources of zoonoses, zoonotic agents and foodborne outbreaks in the European Union in 2008. EFSA Journal. 2010;8(1):1496. 410 pp. Available from: http://www. efsa.europa.eu/en/efsajournal/pub/1496.htm doi:10.2903/j. efsa.2010.1496

10. European Food Safety Authority, European Centre for Disease Prevention and Control. The European Union summary report on trends and sources of zoonoses, zoonotic agents and food borne outbreaks in 2013. EFSA Journal. 2015;13(1):3991. 162 pp. Available from: http://www.efsa.europa.eu/en/efsajournal/ pub/3991.htm doi:10.2903/j.efsa.2015.3991

11. European Food Safety Authority, European Centre for Disease Prevention and Control. The European Union summary report on trends and sources of zoonoses, zoonotic agents and foodborne outbreaks in 2012. EFSA Journal. 2014;12(2):3547. 312 pp. Available from: http://www.efsa.europa.eu/en/efsajournal/ pub/3547.htm doi:10.2903/j.efsa.2014.3547

12. European Commission. Commission decision of 10 July 2009 amending Decision 2000/57/EC on the early warning and response system for the prevention and control of communicable diseases under Decision No 2119/98/EC of the European Parliament and of the Council. 2009/547/EC. Official Journal of the European Union. Luxembourg: Publications Office of the European Union. 14.7.2009:L181. Available from: http://eur-lex.europa.eu/LexUriServ/LexUriServ.do?uri=0J:L:2 009:181:0057:0060:EN:PDF

13. World Health Organization (WHO). Internationa Health Regulations (2005). 2nd ed. Geneva: WHO; 2008. Available from: http://whqlibdoc.who.int/ publications/2008/9789241580410_eng.pdf

14. Regulation (EC) No $178 / 2002$ of the European Parliament and of the Council of 28 January 2002 laying down the general principles and requirements of food law, establishing the European Food Safety Authority and laying down procedures in matters of food safety. Official Journal of the European Union. Luxembourg: Publications Office of the European Union. 1.2.2002:L31. Available from: Available from: http://eur-lex. europa.eu/LexUriServ/LexUriServ.do?uri=0J:L:2002:031:0001: 0024 :EN:PDF

15. Directive $2003 / 99 /$ EC of the European Parliament and of the Council of 17 November 2003 on the monitoring of zoonoses and zoonotic agents, amending Council Decision 90/424/EEC and repealing Council Directive 92/117/EEC. Official Journal of the European Union. Luxembourg: Publications Office of the European Union. 12.12.2003:L325. Available from: Available from: http://eur-lex.europa.eu/LexUriServ/LexUriServ.do?uri= OJ:L:2003:325:0031:0040:EN:PDF

16. United Nations, Department of Economic and Social Affairs. Composition of macro geographical (continental) regions, geographical sub-regions, and selected economic and other groupings. New York, NY: United Nations, Department of Economic and Social Affairs; revised 31 Oct 2013. [Accessed 3 Feb 2014]. Available from: https://unstats.un.org/unsd/ methods/m49/m49regin.htm\#europe

17. Centers for Disease Control and Prevention (CDC). Human Salmonella Typhimurium infections associated with exposure to clinical and teaching microbiology laboratories. Atlanta, GA: CDC; 17 Jan 2012. [Accessed 15 Feb 2014]. Available from: http://www.cdc.gov/salmonella/typhimuriumlaboratory/011712/index.html

18. European Centre for Disease Prevention and Control (ECDC), European Food Safety Authority (EFSA). Multi-country outbreak of Salmonella Stanley infections - update. Joint ECDC/EFSA rapid risk assessment. Stockholm: ECDC; 20 Sep 2012. [Accessed 15 Feb 2014]. Available from: http://ecdc.europa. eu/en/publications/publications/20120921_rra_stanley_ salmonella.pdf

19. MacDonald E, Steens A, Stene-Johansen K, Gillesberg Lassen $\mathrm{S}$, Midgley S, Lawrence J, et al. Increase in hepatitis A in tourists from Denmark, England, Germany, the Netherlands, Norway and Sweden returning from Egypt, November 2012 to March 2013. Euro Surveill. 2013;18(17):20468. PMID:23647624

20. Pan American Health Organization (PAHO). Epidemiological alert: update on cholera in Haiti. Washington, DC: PAHO; 7 Nov 2010. [Accessed 28 Feb 2014]. Available from: http:// www2.paho.org/hq/dmdocuments/2010/epi_alert_2010_7_ November Cholera Outbreak.pdf

21. European Centre for Disease Prevention and Control (ECDC). Survey of National Reference Laboratory (NRL) capacity for six food-and waterborne diseases in EU/EEA countries. Stockholm: ECDC; 2012. Available from: http://www.ecdc.europa.eu/ en/publications/publications/survey-nrl-capacity-for-foodwaterborne-agents.pdf

22. European Statistical System (ESS). EU 2011 population and housing census. Luxembourg: ESS. [Accessed 18 Jun 2015]. Available from: https://ec.europa.eu/CensusHub2/query.do?st ep $=$ selectHyperCube\&qhc $=$ false 